A C TA C H E I CA SCA N D I A V I C A 6 (1952) $1020-1023$

\title{
Studies on Analgesics
}

I. Synthesis of Ethyl 4-(N-Morpholinyl)-1,1-di-( $\alpha$-thienyl)-butyrate and its Pharmacological Properties

NILS LÖFGREN and CLAES TEGNER

Institute of Organic Chemistry and Biochemistry, University of Stockholm, Stockholm, Sweden

Since the systematic work of Bockmühl and Erhardt ${ }^{1}$ on amidone (I) and Nits derivatives, a number of other papers have been published on the synthesis of similar compounds. Speeter, Byrd, Cheney, and Binkley ${ }^{2}$ prepared compound II, which has about the same analgetic effect as amidone and is ten times less toxic. Compound III, structurally very similar to II, was synthesized by Brown, Cook, and Heilbron ${ }^{3}$, and proved to be four times as effective as pethidine.

In this investigation compound IV has been prepared.

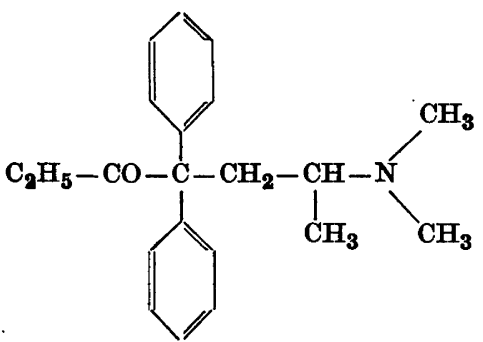

I<smiles>[R12]C([R12])(CCCN1C2(C)CC3(C)C(C)(CC13C)O2)OCC</smiles>

II $\quad R_{1}=R_{2}=$ phenyl-

III $\mathbf{R}_{1}=$ phenyl-, $\quad \mathbf{R}_{\mathbf{2}}=$ thienyl-

IV $\mathbf{R}_{1}=\mathbf{R}_{2}=$ thienyl-

Several attempts were made to obtain the starting material, di-( $\alpha$-thienyl)methane. This compound has already been described in the literature ${ }^{4}$, but the yield never exceeded $10 \%$. Blicke and Burkhalter's method ${ }^{5}$ (in which dithienylmethane was obtained as a by-product on preparing $\alpha$-(chloromethyl)- 
thiophene) was first tried, but though several attempts were made, no dithienylmethane could be isolated. The second method of synthesis was via the ketone, thienone. By letting $\alpha$-thienyllithium react with carbon dioxide we obtained a yield of $67 \%$ of the ketone. However, the compound desintegrated and polymerised on reduction.

The final synthesis of dithienylmethane was carried out in accordance with Haubein's observation ${ }^{6}$ that no bibenzyl is formed when ArLi reacts with $\mathrm{PhCH}_{2} \mathrm{Cl}$. Thus, in the reaction between chloromethylthiophene and thienyllithium a $66 \%$ yield of dithienylmethane was obtained. Ethyl 4(N-morpholinyl)-1,1-di-( $\alpha$-thienyl)butyrate was then made by the method used by Brown, Cook, and Heilbron ${ }^{3}$ for preparing compound II. Hence the monopotassium derivative of dithienylmethane, obtained by the action of potassium in liquid ammonia, was carbethoxylated with diethyl carbonate. The ester thus prepared was condensed with $\mathrm{N}$-(2-chloroethyl)morpholine in the presence of sodamide in dry toluene, yielding the ethyl 4-(N-morpholinyl)-1,1-di-( $a$-thienyl)butyrate (IV).

The compound has an analgetic effect somewhat less than that of pethidine. The toxicity is remarkable low $\left(\mathrm{LD}_{50}>500 \mathrm{mg} / \mathrm{kg}\right.$ white mouse subcut.), morphine and pethidine being more toxic. The local anaestetic effect was compared with that of xylocaine. On rabbit cornea the compound has, under the same conditions ( $\mathrm{pH} \mathrm{3.7)}$, a duration somewhat less than that of xylocaine and a much longer latency time. Further, the compound was tested for its spasmolytic and histaminolytic power. No appreciable effects were found.

\section{EXPERIMENTAL *}

$D i$-( $\alpha$-thienyl)ketone (thienone). In a three-necked flask, equipped with a dropping funnel, a stirrer, a reflux condenser, and a gas inlet tube, was placed a mixture of 0.57 mole $(48 \mathrm{~g}$ ) of thiophene and $200 \mathrm{ml}$ of absolute ether. A stream of dry nitrogen was used to expel the air. To the solution of thiophene was added $300 \mathrm{ml}$ of a $1.35 \mathrm{~N}$ ethereal solution of butyllithium ${ }^{7}$. A vivid reaction took place immediately and the ether refluxed spontaneously. When all butyllithium had been added the solution was kept under gentle reflux for fifteen minutes, by means of a water bath. Then the stream of nitrogen gas was stopped, and carbon dioxide was allowed to bubble into the solution until test for organolithium compound 8 was negative (10 hours). A reddish solution and a white fine grained precipitate that had settled at the bottom were obtained. The content of the vessel was decomposed with water, and the ethereal layer separated and washed completely with $2 \mathrm{~N}$ sodium hydroxide solution (to remove thiophenecarboxylic acid). The ethereal layer was dried $\left(\mathrm{MgSO}_{4}\right)$ and the solvent evaporated. Greyish green needles

*) All our melting points are corrected. 
separated; yield $25 \mathrm{~g}(67 \%)$. On recrystallization from isopropyl ether a constant melting point of $90-90.5^{\circ}$ was obtained.

Several attempts to reduce this compound with sodium and alcohol or by WulffKishner's method failed.

a-(Chloromethyl)thiophene. The compound was made by the method given by Blicke and Burkhalter ${ }^{5}$. As a by-product in the synthesis they reported dithienylmethane. We therefore carried out the synthesis at first chiefly to obtain this hydrocarbon (cf. above). However, we could obtain no isolable amounts of dithienylmethane. Fortunately we were able to use the chief product, chloromethylthiophene, for the synthesis of dithienylmethane (cf. below). However, chloromethylthiophene distilled at $72.5-73.5^{\circ} / 18 \mathrm{~mm}$ contrary to Blicke et al.' $\mathrm{s}^{4}$ statement that the boiling point is $81-82^{\circ} / 18 \mathrm{~mm}$. We found the refractive index, $n_{\mathrm{D}}^{20}$, to be 1.5638 .

We also obtained a second fraction with the same boiling point as that reported by Blicke and Burkhalter ${ }^{5}$. They stated this fraction to be dithienylmethane with the correct m.p. $45-47^{\circ}$. After repeated recrystallizations from petroleum ether, we obtained the compound as small needles with m.p. $35-35.5^{\circ}$, which turned dark blue after a few days. On boiling with methanol the compound gave off hydrogen chloride. Further, our product was without smell, whereas dithienylmethane has a very characteristic odour. It is therefore evident that the second fraction could not be dithienylmethane.

$D i$-( $\alpha$-thienyl)methane. As we could not find any useful method in the literature for preparing dithienylmethane we developed a synthesis using $\alpha$-chloromethylthiophene. The apparatus used was the same as that previously described for $\alpha$-thienylketone. To $150 \mathrm{ml}$ of an ethereal solution of 0.37 mole $(31 \mathrm{~g})$ of thiophene was added 0.26 mole (400 $\mathrm{ml}$ of a $0.64 \mathrm{~N}$ solution of butyllithium) at such a rate as to cause gentle reflux. After 2 hours of heating on a water bath in order to complete the reaction the solution was allowed to cool. 0.32 mole (42 $\mathrm{g})$ of chloromethylthiophene was then added slowly. The ethereal solution was boiled under reflux until test for organolithium compound 8 was negative (40 hours). The content of the vessel was decomposed with water and the ethereal layer separated, washed with water and dried $\left(\mathrm{MgSO}_{4}\right)$. After filtering, the ether was driven off and the residue distilled. The compound was obtained as a faintly yellow oil which solidified rapidly; b.p. $128-130^{\circ} / 11 \mathrm{~mm}$.; yield $31 \mathrm{~g}(66 \%)$. After recrystallization from petroleum ether the dithienylmethane appeared as colourless needles; m.p. $\mathbf{4 4}-\mathbf{4 5 ^ { \circ }}$.

Ethyl di- $\alpha$-thienylacetate, $\mathrm{C}_{12} \mathrm{H}_{12} \mathrm{O}_{2} \mathrm{~S}_{2}$ (252.3). Ammonia gas was introduced through a potassium hydroxide drying tube into a three-necked flask of $500 \mathrm{ml}$, equipped with a dropping funnel, a Hershberg stirrer and a condenser for cooling with freezing mixture (trichloroethylene and solid carbon dioxide). The condenser was kept at $-50^{\circ}$ and the flask at $-35^{\circ}$. When the flask contained $300 \mathrm{ml}$ of liquid ammonia the cooling bath was taken away and 0.18 mole $(7.2 \mathrm{~g})$ of potassium cut into pieces was added for a period of half an hour. After onehour the blue colour had disappeared. The condenser with freezing mixture was replaced by an ordinary water cooled reflux condenser and 0.17 mole $(30 \mathrm{~g})$ of dithienylmethane in $375 \mathrm{ml}$ of ether was added drop by drop for one and a half hours. On the addition the solution turned brown. When half the volume of the dithienylmethane solution had been added the reaction mixture was heated to remove ammonia. After the solution had reached room temperature 0.084 mole $(9.9 \mathrm{~g})$ of diethyl carbonate was added. The solution was boiled for 12 hours under reflux. It was then decomposed with $300 \mathrm{ml}$ of diluted acetic acid $(5 \%)$. The ethereal layer was separated and washed with water. The solution was dried $\left(\mathrm{MgSO}_{4}\right)$ and the ether driven off, leaving a reddish brown 
viscous oil (35 g). On fractionating in vacuo a fore-run of $15 \mathrm{~g}$ of dithienylmethane was collected. The fraction of ethyl dithienylacetate had a boiling point of $124-125^{\circ} / 0.6 \mathrm{~mm}$.; $n_{\mathrm{D}}^{20}=1.5728$; m.p. $\sim 7^{\circ}$; yield $12 \mathrm{~g}(28 \%)$.

$\begin{array}{lll}\text { Calc. C } 57.1 & \text { H } 4.80 & \text { S } 25.4 \\ \text { Found } & 57.1 & 4.94\end{array}$

Ethyl 4-(N-morpholinyl)-1,1-di-( $\alpha$-thienyl)butyrate, $\mathrm{C}_{18} \mathrm{H}_{23} \mathrm{NO}_{3} \mathrm{~S}_{2}$ (365.5). To a $100 \mathrm{ml}$ flask, equipped with a stirrer and a reflux condenser with a potassium hydroxide drying tube, was added $0.0284 \mathrm{~mole}(7.15 \mathrm{~g})$ of the above mentioned ester, 0.0311 mole $(4.65 \mathrm{~g})$ of $\mathrm{N}$-(2-chloroethyl)morpholine and 0.0310 mole $(1.21 \mathrm{~g})$ of sodamide suspended in $35 \mathrm{ml}$ of dry toluene. On the addition of sodamide the solution turned brown, and on heating the colour deepened and ammonia was given off. The temperature of the mixture was kept at $120-130^{\circ}$ for two hours, after which time the solution had turned light yellow. The toluene solution was shaken sufficiently with $2 N$ hydrochloric acid and from the combined extracts the base was liberated by addition of ammonia (1:1) and taken up in ether. After washing with water and drying $\left(\mathrm{Na}_{2} \mathrm{SO}_{4}\right)$, the ether was driven off leaving a reddish brown oil $(8.8 \mathrm{~g})$, which was fractionated by distillation. The compound was obtained as a colourless oil; b.p. $164-164^{\circ} / 0.01 \mathrm{~mm}$.; $n_{\mathrm{D}}^{20}=1.5676$; yield $5.85 \mathrm{~g}(57 \%)$.

Calc. C $59.1 \quad$ H 6.34

Found " 59.0 "6.31

Nitrate, $\mathrm{C}_{18} \mathrm{H}_{24} \mathrm{~N}_{2} \mathrm{O}_{6} \mathrm{~S}_{2}$ (428.5). Rhombic laths from propanol; m.p. 145-146 ${ }^{\circ}$. The salt is slightly soluble in water.

$\begin{array}{lrr}\text { Calc. C } 50.4 & \text { H } 5.64 \\ \text { Found " } 50.3 & \text { " } 5.60\end{array}$

\section{SUMMARY}

Ethyl 4-(N-morpholinyl)-1,1-di-( $\alpha$-thienyl)butyrate was prepared and proved itself to have a distinctly analgetic effect and a remarkably low toxicity.

Acknowledgments are made to A.-B. Astra for financial support. We wish to express our sincere gratitude to Dr. S. Wiedling of the Biological Department of Astra and to Dr. L. Olsson of the Royal Veterinary College.

\section{REFERENCES}

1. Bockmühl, M., and Erhardt, G. Ann. 561 (1948) 52.

2. Speeter, M. E., Byrd, W. M., Cheney, L. C., and Binkley, S. B. J. Am. Chem. Soc. 71 (1949) 57.

3. Brown, D. J., Cook, A. H., and Heilbron, Ian J. Chem. Soc. (1949) Suppl. 1, 113.

4. Peter, A. Ber. 17 (1884) 1345.

5. Blicke, F. F., and Burkhalter, J. H. J. Am. Chem. Soc. 64 (1942) 477.

6. Haubein, A. H. Iowa State Coll. J. Sci. 18 (1943) 48.

7. Gilman, H., and Shirley, D. A. J. Am. Chem. Soc. 71 (1949) 1870.

8. Gilman, H., and Schulze, F. J. Am. Chem. Soc. 47 (1925) 2002.

Received July 25, 1951. 